\title{
A Comparative Study between Fentanyl and Dexamethasone as Adjuvants in Supraclavicular Brachial Plexus Block With 0.5\% Levobupivacaine
}

\author{
Dr. K.Nagabhushanam, Dr. Ponnapalli.S.S.S.Madhav ${ }^{*}$, Dr. SK. Fathimunnisa, Dr. J.Mrudula, Dr. Uma Manjula
}

Department of Anaestesiology, Guntur Medical College, Guntur, Andhra Pradesh, India

DOI: $10.36347 /$ sasjs.2020.v06i01.004

| Received: 04.01.2020 | Accepted: 19.01.2020 | Published: 28.01.2020

*Corresponding author: Dr. Ponnapalli.S.S.S.Madhav

\section{Abstract}

Original Research Article

Different additives have been used to prolong brachial plexus block. This is a prospective, randomized, study to compare the block characteristics between Fentanyl and Dexamethasone as adjuvants in supraclavicular brachial plexus block with $0.5 \%$ Levobupivacaine. Sixty patients of ASA grades 1 and 2 were randomly divided into two groups of thirty patients each, group 1 received $0.5 \%$ Levobupivacaine $(2 \mathrm{mg} / \mathrm{kg})$ with $2 \mathrm{~mL}$ of $100 \mathrm{mcg}$ Fentanyl and group 2 received $0.5 \%$ Levobupivacaine $(2 \mathrm{mg} / \mathrm{kg}$ ) with $2 \mathrm{~mL}$ of $8 \mathrm{mg}$ Dexamethasone. The groups were compared in terms of onset of sensory block and onset of motor block, duration of sensory block and motor block and duration of analgesia. The onset of sensory block is significant between the two groups $8.43 \pm 1.89$ mins in group 2 as compared to $10.1 \pm 1.3 \mathrm{mins}$ in group 1 which is statistically significant (0.0002), and the onset of motor block is earlier in group 2 , mean time for onset of motor block in group 1 is $14.4 \pm 1.73 \mathrm{mins}$ as opposed to $12.93 \pm 1.48 \mathrm{mins}$. which is statistically significant ( $\mathrm{p}$ value < 0.0001). The mean duration of sensory block and mean duration of motor block both are prolonged in group 2. Mean duration of motor block in group 1 is $774.8 \pm 42.74$ mins and $851.29 \pm 49.301$ mins in group 2 , which is statistically significant ( $\mathrm{p}$ value $<0.0001$ ). Mean duration of sensory block in group 1 is $941.29 \pm 49.8 \mathrm{mins}$ and $1030.32 \pm 49.08$ mins in group 2 , which is statistically significant ( $\mathrm{p}$ value $<0.0001$ ).

Keywords: Levobupivacaine, Fentanyl, Dexamethasone, Supraclavicular brachial plexus block, sensory block, motor block, post-operative analgesia.

Copyright @ 2020: This is an open-access article distributed under the terms of the Creative Commons Attribution license which permits unrestricted use, distribution, and reproduction in any medium for non-commercial use (NonCommercial, or CC-BY-NC) provided the original author and source are credited.

\section{INTRODUCTION}

Pain is as old as life. Human being, as we think as the highest developed organism, is the strongest feeler of pain. It has been a man`s endeavor to kill and lessen pain from a very early age.

Regional nerve blocks are based on the concept that pain is conveyed by nerve fibers, which are susceptible to interruption anywhere along their pathway. Regional anaesthesia is an excellent adjunct or alternative to General anaesthesia for extremity surgery.

Post anesthetic side effects like nausea, vomiting, and other side effects of general anaesthesia such as atelectasis, hypotension, ileus, and DVT are reduced. It provides superior postoperative analgesia and hastens recovery from anaesthesia. Although regional anaesthesia has an opioid-sparing effect, occasionally, postoperative analgesic duration is not adequate to compensate for the acute nociception associated with surgery in the early perioperative phase of healing.
The duration of sensory nerve blockade, and therefore analgesia with single-shot regional anaesthesia is relatively short-lived. Efforts to prolong brachial plexus block duration by increasing the local anesthetic dose are limited as the therapeutic window is narrow and indeed may not be effective as recent studies have demonstrated equivalent analgesic duration with volumes as low as $5 \mathrm{ml}$.

Strategies to prolong brachial plexus block analgesia beyond the pharmacological duration of the local anesthetic used include placement of indwelling perineural catheters to allow prolonged infusion or the co-administration of adjuvants such as Epinephrine, $\alpha 2$ agonists (i.e. Clonidine and Dexmedetomidine), Ketamine, Neostigmine, Morphine, Pethidine, Butorphanol, Tramadol, Buprenorphine, Midazolam, or the Corticosteroid Dexamethasone. Indwelling catheter techniques can be very effective and provide analgesia for several days, but their utility is limited by technical challenges with placement, inherent secondary failure rate, difficulties with catheter removal, or rarely 
infection. Furthermore, not all anesthetists have the subspecialty training required to perform advanced indwelling catheter techniques, nor is there universal capability to administer and manage an outpatient perineural catheter program.

Levobupivacaine has less systemic toxicity than Bupivacaine as it is a pure enantiomer.

\section{MATERIALS AND METHODS}

After obtaining approval from the hospital academic and ethics committee, written and informed valid consent, 60 patients were enrolled in the study. The study population included patients of either sex, ASA grade 1 and 2 in the age range of 18- 70 years. All patients were posted for upper extremity surgeries below the shoulder joint and received brachial plexus block by a supraclavicular approach.

\author{
Study design \\ The study was a prospective randomized case- \\ control study.
}

\section{Study period}

January 2018 to December 2019.

\section{Inclusion criteria}

- Age group 18-70 years of either sex

- ASA grade I and II

- Patients who are undergoing upper limb surgery below the shoulder joint.

\section{Exclusion criteria}

- Consent not given

- $\quad$ ASA Grade III and IV

- Any bleeding disorder and patient on anticoagulants

- Severe respiratory disease

- Neuro deficit involving brachial plexus

- Local infection at the injection site

- Patients with a history of peptic ulcer disease, diabetes mellitus, hepatic or renal failure (contraindication to steroids)

- History of allergy to local anesthetic

In both groups, the volume of local anesthetic injected is not constant and varies according to the bodyweight of the patients. In each patient, a thorough history was elicited. The patient was clinically examined in detail and investigated.

\section{LEVOBUPIVACAINE}

Levobupivacaine is a local anesthetic of the amide-type. Levobupivacaine is ([2S]-1-butyl-N- [2, 6dimethylphenyl] piperidine-2-carboxamide) and is an amino-amide local anesthetic drug belonging to the family of n-alkyl substitute pipecoloxylidide. Its chemical formula is $\mathrm{C}_{18} \mathrm{H}_{28} \mathrm{~N}_{20}$. Molecular weight is 324.9 and pKa 8.09. Levobupivacaine stabilizes the neuronal membrane by inhibiting the ionic fluxes required for the initiation and conduction of impulses, thereby effecting local anesthetic action. Levobupivacaine Shares pharmacodynamic properties of other local anesthetics. Systemic absorption produces CNS and CVS toxicity. The Effect on CNS might cause tinnitus, restlessness, seizures, and coma. Toxic blood concentrations depress cardiac conduction and excitability, which may lead to atrioventricular block and arrhythmias and cardiac arrest.

\section{FENTANYL}

Fentanyl is an opioid analgesic interacting primarily with the opioid mu receptor. Its chemical formula is $\mathrm{C} 22 \mathrm{H} 28 \mathrm{~N} 2 \mathrm{O}$. Fentanyl molecules target a subclass of the opioid receptor system in the body, which are localized in the brain within specialized neuroanatomical structures. It is a selective mu receptor agonist and can activate other receptors like delta and kappa. Activation of these receptors produces analgesia.

\section{DEXAMETHASONE}

Dexamethasone sodium phosphate, a synthetic adrenocortical steroid, is a white or slightly yellow, crystalline powder. It is freely soluble in water and is exceedingly hygroscopic. The molecular weight is 516.41. It is designated chemically as 9-fluoro-11ß, 17dihydroxy-16a-methyl-21-(phosphonooxy) pregna-1, 4diene-3, 20-dione disodium salt. The mechanism of the analgesia induced by corticosteroids is not fully understood. This effect is suspected to be mediated by their anti-inflammatory effects.

\author{
Investigations \\ Complete hemogram \\ X-ray chest \\ Blood urea nitrogen, Blood Sugar \\ Electrocardiogram, if age $>40$ years
}

\section{Monitoring}

Standard monitors were attached

- Pulse oximetry for saturation (SpO2)

- ECG for heart rate and rhythm

- NIBP

An intravenous drip was started before undertaking the procedure, which continued throughout the length of surgery. Vital parameters were observed throughout the procedure and oxygen at the rate of $6 \mathrm{~L} / \mathrm{min}$ administered through the oxygen mask.

Sixty patients were divided into two groups of thirty each and group 1 received $0.5 \%$ Levobupivacaine $(2 \mathrm{mg} / \mathrm{kg})$ and $2 \mathrm{~mL}$ of $100 \mathrm{mcg}$ of Fentanyl and group 2 received $0.5 \%$ Levobupivacaine and $2 \mathrm{~mL}$ of $8 \mathrm{mg}$ Dexamethasone. The block was performed using a peripheral nerve stimulator technique. 
A successful block was defined as complete sensory and motor blockade in all regions of median, ulnar, redial, and musculocutaneous nerve distribution. sensory block was assessed using Verbal Analogue Score(0-no pain and 100-most painful), using the blunt end of $27 \mathrm{G}$ needle at $0 \mathrm{~min}, 5 \mathrm{~min}, 10 \mathrm{~min}, 15 \mathrm{~min}$, $60 \mathrm{~min}, 120 \mathrm{~min}, 180 \mathrm{mins}$ and the motor block was measured using Modified Lovette Rating Scale Score(0complete paralysis and 6-normal muscular force), and assessed at $0 \mathrm{~min}$, $5 \mathrm{~min}, 10 \mathrm{~min}, 15 \mathrm{~min}$, 60min, $120 \mathrm{~min}$, 180 mins.

None of the patients had bradycardia, hypotension, pruritis, and respiratory depression following the administration of Fentanyl along with local anesthetic like Levobupivacaine.

\section{STATISTICAL ANALYSIS}

Basic descriptive statistics have been used to study the central tendency and the variability among the variables. Results are expressed as means and standard deviation or numbers and percentages. Two sample ttest of difference between two means was used to analyze the differences between various parameters that were used in the cases and controls. A P-value of $<0.05$ is considered significant. Unpaired $\mathrm{t}$ test, Statistical presentation and analysis of the present study were conducted, using SPSS software version 21.0 (IBM Corporation, Armonk, NY, USA) statistics.

\section{RESULTS}

Table-1: Comparisons of age and anthropometric measures in different study groups

\begin{tabular}{|l|l|l|l|l|}
\hline \multicolumn{2}{|l|}{} & GROUP 1 (FENTANYL) & GROUP 2(DEXAMETHA) & P VALUE \\
\cline { 1 - 3 } AGE IN YEARS & $39.66 \pm 11.609$ & $40.266 \pm 11.623$ & 0.84 (not significant) \\
\hline WEIGHT IN KGS & $68.3 \pm 5.066$ & $68.6 \pm 4.484$ & 0.809 (not significant) \\
\hline SEX & MALE & 15 & 16 & not significant \\
\hline \multicolumn{2}{|l|}{ FEMALE } & 15 & 14 & \\
\cline { 1 - 2 } DURATION OF SURGERY IN MINS & $98.666 \pm 24.45$ & $96.76 \pm 25.178$ & 0.76 (not significant) \\
\hline
\end{tabular}

Table-2: Comparison of onset and duration of sensory and motor block in different study groups

\begin{tabular}{|l|l|l|l|}
\hline & GROUP 1(FENTANY) & GROUP 2(DEXAMET) & P VALUE \\
\hline Onset of sensory block & $10.1 \pm 1.3 \mathrm{mins}$ & $8.43 \pm 1.89 \mathrm{mins}$ & 0.0002 (significant) \\
\hline Duration of sensory block & $941.29 \pm 49.8 \mathrm{mins}$ & $1030.32 \pm 49.08 \mathrm{mins}$ & $<0.0001$ (significant) \\
\hline Onset of motor block & $14.4 \pm 1.73 \mathrm{mins}$ & $12.93 \pm 1.48 \mathrm{mins}$ & $<0.0001$ (significant) \\
\hline Duration of motor block & $774.8 \pm 42.74 \mathrm{mins}$ & $851.29 \pm 49.301 \mathrm{mins}$ & $<0.0001$ (significant) \\
\hline
\end{tabular}

Table 1, illustrates that, there is no difference between the two groups in terms of anthropometric measures like age, weight, sex of the patients and duration of surgery and hence the both groups are comparable statistically.

Table 2, illustrates that the onset of sensory block in group 2 receiving Levobupivacaine with Dexamethasone is $8.43 \pm 1.89 \mathrm{mins}$, is earlier compared to group 1 receiving Levobupivacaine with Fentanyl which is $10.1 \pm 1.3$ mins. Onset of motor block is also earlier in group 2 which is about $12.93 \pm 1.48 \mathrm{mins}$ compared to $14.4 \pm 1.73$ mins in group 1 . Duration of sensory block is prolonged in group 2 receiving Levobupivacaine with Dexamethasone, $1030.32 \pm 49.08$ mins, compared to group 1 receiving Levobupivacaine with Fentanyl, 941.29 \pm 49.8 mins. Duration of motor block is also prolonged in group 2, mean duration of motor block in group 1 is $774.8 \pm 42.74 \mathrm{mins}$ and in group 2 is $851.29 \pm 49.301 \mathrm{mins}$.

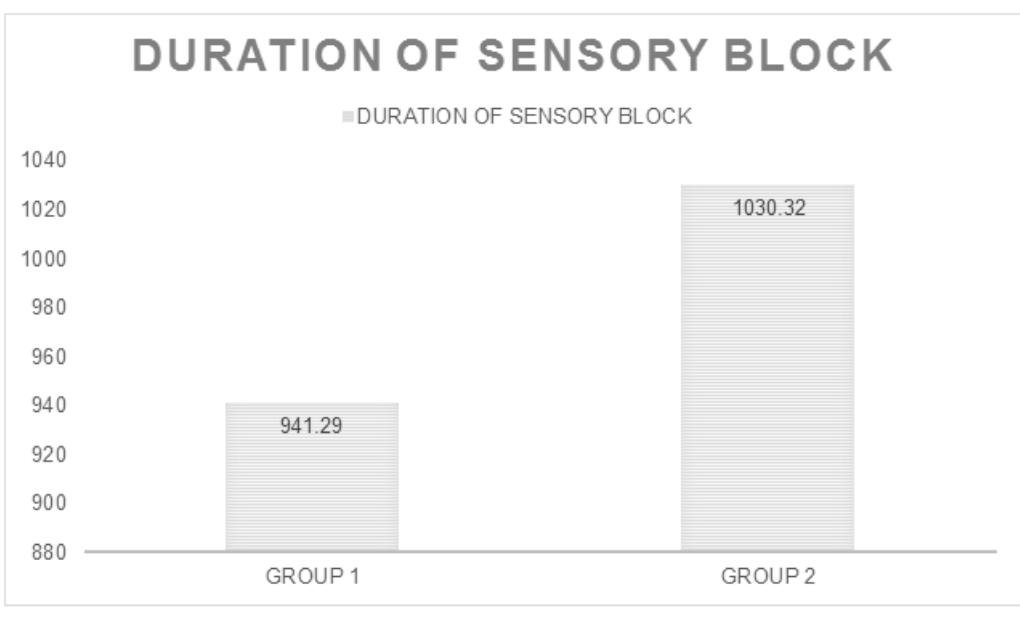


DURATION OF MOTOR BLOCK

\section{=DURATION OF MOTOR BLOCK}

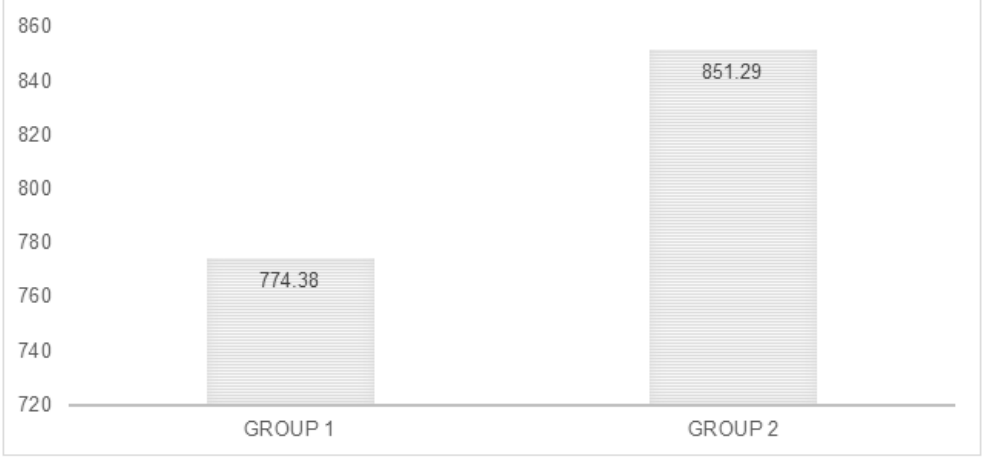

\section{DISCUSSION}

This is a controlled, randomized, prospective study. Sixty patients posted for upper limb surgeries below the shoulder joint were given brachial plexus block by supraclavicular approach using nerve stimulation technique. The patients were randomly allocated into two groups using standard randomization code.

Onset of sensory block is earlier in group receiving Levobupivacaine with Dexamethasone, These findings in terms of onset of sensory block concur with the studies done by Shrestha BR, Maharjan SK, Tabedar S. In their study, onset of sensory block was 10-30 minutes in local anesthetic group (mean $18.15 \pm$ $4.25 \mathrm{~min}$ ) and 10-20 minutes (mean $14.5 \pm 2.10 \mathrm{~min}$ ) in the local anesthetic plus steroid group and found statistically significant difference between two groups. In another study done by Biradar et al. a statistically significant difference in the onset of the sensory block $(13.4 \pm 2.8 \mathrm{~min}$ vs $16 \pm 2.3 \mathrm{~min})$ was observed which is in concurrence with the present study. In the study done by Islam SM et al. also a statistically significant difference in the onset of the sensory block $(9.89 \pm 1.87$ min vs $11.64 \pm 2.19 \mathrm{~min}$ ) was observed which is also in concurrence with the present study.

Onset of motor block is earlier in group receiving Levobupivacaine with Dexamethasone compared to group receiving Levobupivacaine with Fentanyl, The findings in terms of onset of motor block concur with the study by Pathak et al. [6] where the onset of motor block in dexamethasone group was 15.8 $\pm 5.6 \mathrm{~min}$ and $16.6 \pm 5.11 \mathrm{~min}$ in the control group. In the study done by Shrestha et al. [11], a significant difference in the onset of the motor block $(12.9 \pm 1.49$ vs $13.93 \pm 1.96 \mathrm{~min}$ ) was observed which is also in concurrence with the present study.

Duration of sensory block is prolonged in group 2 compared to group 1, The above findings, in terms of duration of analgesia concur with the studies done by Shrestha et al. Pathak et al. and Yadav et al. indicating that Dexamethasone used as an adjuvant in brachial plexus block clearly prolongs the duration of sensory blockade.

Duration of motor block is also prolonged in group 2 as compare to group 1, The above findings, in terms of duration of analgesia concur with the studies done by Shrestha et al. Pathak et al. and Yadav et al. indicating that Dexamethasone used as an adjuvant in brachial plexus block clearly prolongs the duration of sensory blockade.

None of the patients had bradycardia or tachycardia, hypertension or hypotension following administration of dexamethasone along with local anaesthetic agent. These findings corroborated with that of Choi et al. Persec et al. and Shreshtha et al. who also found no significant difference in hemodynamic parameters on addition of Dexamethasone or Fentanyl to Local Anesthetics.

\section{LIMITATIONS OF THE PRESENT STUDY}

- Ultrasound guided block is not used because of unavailability in this institution during the study period.

- Impact of dexamethasone on glucose homeostasis was not studied.

- Effects of dexamethasone on wound healing were not studied.

- Chronic neurological effects of dexamethasone are also not studied.

\section{CONCLUSION}

Addition of Dexamethasone to Levobupivacaine as compared to Fentanyl results in faster onset of sensory and motor blocks and prolongation of sensory block and motor block and there were no significant hemodynamic parameters in both groups.

\section{REFERENCES}

1. Matas R. Local and regional anesthesia: A retrospect and prospect. The American Journal of Surgery. 1934 Aug 1;25(2):362-78. 
2. Wright HW. Anæsthesia of the brachial plexus. British Journal of Surgery. 1926 Jul;14(53):160-7.

3. Ansbro FP. A method of continuous brachial plexus block. The American Journal of Surgery. 1946 Jun 1;71(6):716-22.

4. Winnie AP, Colline VJ. The subclavian perivascular technique of brachial plexus anaesthesia. Anesthesiology. 1964; 25:353-63.

5. Alarasan AK, Agrawal J, Choudhary B, Melhotra A, Uike S, Mukherji A. Effect of dexamethasone in low volume supraclavicular brachial plexus block: A double-blinded randomized clinical study. J Anaesthesiol Clin Pharmacol. 2016;32:234-9.

6. Pathak RG, Satkar AP, Khade RN. Supraclavicular brachial plexus block with and without dexamethasone-a comparative study. International journal of scientific and research publications. 2012 Dec;2(12):1-7.

7. Kaniyil S, Radhakrishnan P. Does fentanyl prolong the analgesia of local anesthetics in brachial plexus block? A randomized controlled study. Int J Res Med Sci. 2017 Feb;5:583-7.

8. Saryazdi H, Yazdani A, Sajedi P, Aghadavoudi O. Comparative evaluation of adding different opiates (morphine, meperidine, buprenorphine, or fentanyl) to lidocaine in duration and quality of axillary brachial plexus block. Advanced biomedical research. 2015;4.

9. Chavan SG, Koshire AR, Panbude P. Effect of addition of fentanyl to local anesthetic in brachial plexus block on duration of analgesia. Anesth Essays Res. 2011;5:39-42.

10. Brummett CM, Williams BA. Additives to local anesthetics for peripheral nerve blockade. Int Anesthesiol Clin. 2011;49:104-16.

11. Ammar AS, Mahmoud KM. Effect of adding dexamethasone to bupivacaine on transversus abdominis plane block for abdominal hysterectomy: A prospective randomized controlled trial. Saudi journal of anaesthesia. 2012 Jul;6(3):229. 